\title{
Saberes e práticas tradicionais na extração e cultivo de macroalgas marinhas
}

Esse estudo teve o objetivo de investigar os saberes e práticas tradicionais presentes nas atividades de extrativismo dos bancos naturais e cultivo de macroalgas marinhas no Rio Grande do Norte. O estudo foi realizado por meio de entrevistas semiestruturadas utilizando questionário composto por assuntos que abordavam questões relacionadas as práticas produtivas, aspectos sociais, manejo das macroalgas e conhecimentos referentes aos ecossistemas costeiros. Além das entrevistas, foi realizado o acompanhamento das atividades produtivas desenvolvidas pelos participantes envolvidos na pesquisa. Dentre os registros obtidos, podemos destacar os saberes tradicionais da atividade extrativista, os conhecimentos empíricos relacionados à ecologia e ciclo de vida das macroalgas. No que se refere a produção das algas cultivadas, ficou constatada que essas práticas contribuem para a diminuição da pressão exercida sobre os bancos naturais, possibilitando a manutenção e a recuperação das populações naturais de macroalgas na área estudada. Além disso, ficou evidenciado que as atividades desenvolvidas pela comunidade têm contribuído para o desenvolvimento econômico, social e ambiental da região. Em conclusão, foi possível verificar que os saberes e práticas tradicionais do extrativismo e cultivo de algas, influenciam de forma positiva na conservação dos recursos naturais, e o seu uso de forma racional é extremamente importante para a perpetuação dos saberes dessas populações tradicionais.

\section{Traditional knowledge and practices in seaweed harvesting and farming}

\begin{abstract}
This study aimed to investigate the traditional knowledge and practices present in the extractive activities of natural beds and seaweed farming in Rio Grande do Norte. The study was carried out through semistructured interviews using a questionnaire composed of subjects that addressed issues related to productive practices, social aspects, management of seaweed and knowledge related to coastal ecosystems. In addition to the interviews, the productive activities developed by the participants involved in the research were monitored. Among the records obtained, we can highlight the traditional knowledge of the harvest activity, the empirical knowledge related to the ecology and life cycle of seaweed. Regarding the production of seaweed farmed, it was found that these practices contribute to the reduction of pressure on natural beds, enabling the maintenance and recovery of natural populations of seaweed in the studied area. In addition, it was evident that the activities developed by the community have contributed to the economic, social and environmental development of the region. In conclusion, it was possible to verify that the traditional knowledge and practices of seaweed farming and harvesting, positively influence the conservation of natural resources, and their use in a rational way is extremely important for the perpetuation of the knowledge of these traditional populations.
\end{abstract}

Keywords: Harvesting; Extractive activities; Gracilaria birdiae; Seaweed farming.

Topic: Planejamento, Gestão e Políticas Públicas Ambientais

Reviewed anonymously in the process of blind peer
Received: 06/10/2020

Approved: $\mathbf{2 8 / 1 1 / 2 0 2 0}$
Ana Beatriz Gomes Ferreira (iD)

Universidade Federal do Rio Grande do Norte, Brasil

http://lattes.cnpq.br/3428643449624579

http://orcid.org/0000-0003-1532-2320

beatriz_biologia@hotmail.com

Marcella Araújo do Amaral Carneiro (iD)

Universidade Federal do Rio Grande do Norte, Brasil

http://lattes.cnpq.br/2397478558863939

http://orcid.org/0000-0002-9823-3384

marcellamaralcarneiro@gmail.com

Eliane Marinho Soriano (id

Universidade Federal do Rio Grande do Norte, Brasil

http://lattes.cnpq.br/2017823516741199

http://orcid.org/0000-0001-6736-3795

elianemsoriano@gmail.com

\section{Referencing this:}

FERREIRA, A. B. G.; CARNEIRO, M. A. A.; SORIANO, E. M.. Saberes e práticas tradicionais na extração e cultivo de macroalgas marinhas. Revista Ibero Americana de Ciências Ambientais, v.11, n.6, p.661671, 2020. DOI: http://doi.org/10.6008/CBPC21796858.2020 .006 .0053

DOI: 10.6008/CBPC2179-6858.2020.006.0053 


\section{INTRODUÇÃO}

As macroalgas marinhas têm desempenhado um papel importante nas comunidades costeiras durante séculos devido às suas diversas aplicabilidades. O primeiro registro da sua utilização foi datado em 14.600 a.C. (DILLEHAY et al., 2008), e desde então, elas são coletadas nas praias de várias regiões do mundo para usos tradicionais, tais como alimentos, forragem para animais e adubo para a agricultura. Hoje, as algas são usadas em uma infinidade de aplicações devido à expansão global das indústrias baseadas em hidrocolóides, cosméticos e suplementos alimentares (FORSTER et al., 2015; FAO, 2017). Atualmente, uma grande parte da biomassa algal comercializada no mundo é proveniente de atividades extrativistas e de cultivos familiares realizados pelas populações tradicionais que vivem nas áreas costeiras (BEZERRA et al., 2010; REBOURS et al., 2014; SORIANO, 2017).

Umas das características marcantes das populações tradicionais são o uso e o manejo dos recursos naturais e o desenvolvimento de atividades produtivas, em um processo de dependência da natureza a partir do qual se constrói um modo de vida (PEREIRA et al., 2010). Durante esse processo, o conhecimento empírico, relacionado aos recursos naturais, adquirido através das experiências vividas e produzem o saber tradicional (GEERTZ, 1997). Tais saberes podem ser compreendidos como um conjunto de conhecimentos sobre a vida e o meio ambiente, podendo ser externados por meio de crenças, rituais, mitos, usos e práticas de um grupo social (LÉVI-STRAUSS, 1989; ARRUDA et. al. 2001; DIEGUES, 2002; REYES-GARCÍA, 2009, CALEGARE et al., 2014; FERNANDES et al., 2015). Esses saberes são transmitidos, de geração em geração, através de observações práticas do cotidiano e das relações de aprendizado por meio da educação informal, contribuindo para uma relação harmoniosa entre o homem e a natureza (DIEGUES, 2002; MOTA et al., 2008; SILVA et al., 2013; HORA et al., 2015).

Historicamente as atividades de colheita manual dos bancos naturais apoiam-se no trabalho comunitário, na tradição familiar e no contato direto com o meio ambiente (BEZERRA et al., 2010; SORIANO, 2017). Até hoje, diversas comunidades ao redor do mundo ainda praticam essa atividade, valorizando o conhecimento tradicional em torno da colheita (O'CONNELL-MILNE et al., 2015). No entanto, com a ameaça ao esgotamento dos bancos naturais, diversas comunidades tem gerenciado seus recursos costeiros através da introdução de novas culturas (KITOLELEl et al., 2016). Como exemplo, podemos citar o cultivo no mar de macroalgas marinhas, que tem sido tradicionamente cultivada por decádas em vários paises (BEZERRA, 2008). Essa nova forma de adquirir os recursos marinhos são respostas adaptativas da comunidade, que tem como base a tradição cultural e seus conhecimentos tradicionais (KITOLELEl et al., 2016).

Na praia de Rio do Fogo (RN) acontece a atividade extrativista de colheita e cultivo comercial da macroalga marinha Gracilaria birdiae, uma espécie amplamente explorada devido à sua grande importância econômica (TORRES et al., 2019). Essas atividades envolvem saberes que são adquiridos através de tradições locais, no contato direto com o ecossistema marinho e na obtenção direta de conhecimentos transmitidos por seus antepassados. Esse conhecimento tem sido repassado através de uma relação de aprendizado entre os membros da família, na tentativa de transmitir seu saber para as gerações futuras, desempenhado um 
papel importante na identidade das comunidades costeiras (BEZERRA et al., 2010; SORIANO, 2017).

Existe uma necessidade crescente de pesquisas sobre os conhecimentos das comunidades tradicionais, para promover ações coletivas que garantam uma sustentabilidade no uso de recursos naturais (KITOLELEl et al., 2016). Diante desse contexto, o resgate dos saberes e práticas tradicionais das comunidades que exploram a natureza pode auxiliar na identificação e construção de novos parâmetros que favoreçam o desenvolvimento econômico, social e ambiental.

Nesse sentido, o presente estudo teve como objetivo identificar os saberes e práticas dos extrativistas e dos cultivadores de macroalgas marinhas da praia de Rio do Fogo (RN) e de que forma esses saberes interferem em suas práticas sociais cotidianas.

\section{METODOLOGIA}

\section{Local do estudo}

O município de Rio de Fogo ( $05^{\circ} 16^{\prime} 22^{\prime \prime} \mathrm{S}-35^{\circ} 22^{\prime} 57^{\prime \prime} \mathrm{W}$ ) localiza-se na mesorregião do Leste Potiguar e na microrregião do Litoral Norte do estado do Rio Grande do Norte (Figura 1). O município possui um total de 151,10 km² de área territorial, com uma população estimada de 10.789 habitantes. A praia de Rio do Fogo, localizada nesse município, é uma típica vila de pescadores, caracterizada por uma grande diversidade ambiental e de atividades, sobretudo extrativistas. Grande parte da comunidade vive exclusivamente da exploração de organismos aquáticos, seja para o consumo próprio ou para sua comercialização. Os principais organismos explorados na região são lagostas, polvo, peixes e extração de algas marinhas dos bancos naturais. Em 2006, foi implantado um projeto de cultivo da macroalga Gracilaria birdae na região. O projeto foi financiado pelo governo brasileiro (UTF/BRA/066/BRA) e teve como objetivo consolidar e expandir o cultivo de algas. A partir desse projeto foi formada a Associação das Maricultoras de algas de Rio do Fogo (AMAR), que passaram a comercializar algas produzidas em sistemas de cultivo flutuantes.

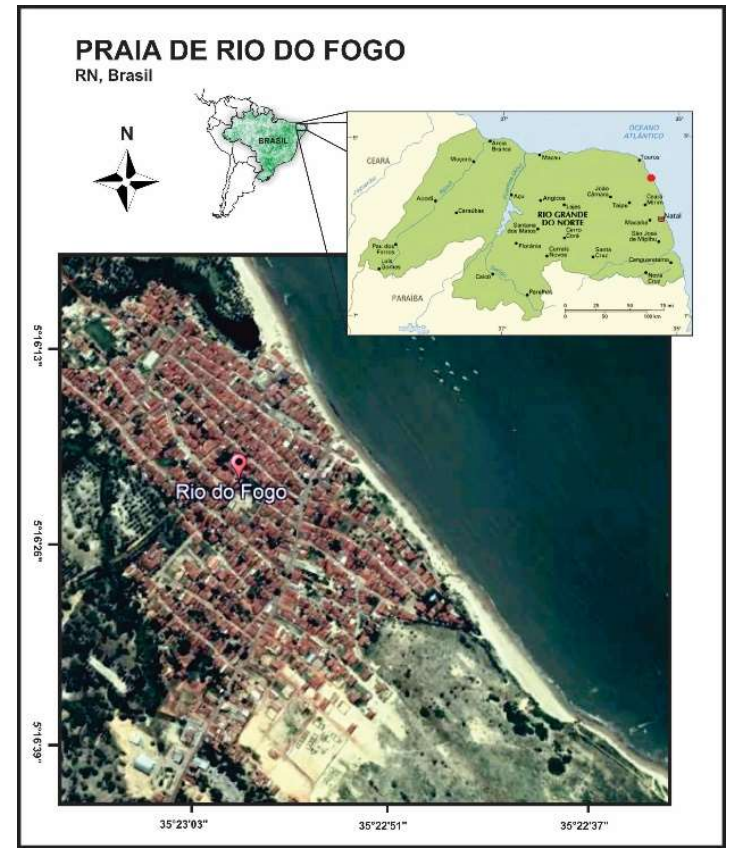

Figura 1: Localização geográfica da praia de Rio do Fogo, Rio Grande do Norte, Brasil. 


\section{Coleta e análise de dados}

Os dados foram obtidos através de entrevistas semiestruturadas baseadas na metodologia de Meksenas (2002) e Viertler (2006), na qual se reverte como uma técnica flexível e informal. Esta abordagem utiliza tópicos fixos, que ao decorrer das entrevistas, podem ser redefinidos, possibilitando o direcionamento do diálogo para as questões investigadas.

O público alvo da pesquisa foram os extrativistas e maricultores (cultivadores) de algas marinhas da localidade, totalizando quatorze participantes ( $100 \%$ do público alvo). A coleta de dados ocorreu nas residências dos entrevistados, entre o período de dezembro de 2018 a março de 2019, a partir da abordagem direta e seguindo como roteiro um questionário. Esse material foi composto por 40 indagações, relacionadas às questões sociais, história de vida, tópicos sobre as práticas produtivas, manejo da espécie $G$. birdiae e conhecimentos empíricos da comunidade local referente os ecossistemas costeiros. Além das entrevistas, foram feitas observações durante o acompanhamento das atividades práticas da coleta de algas dos bancos naturais e do cultivo no mar.

Todo o material etnográfico (gravações, transcrições, questionários e fotografias), foi analisado qualitativamente, considerando-se todas as informações citadas pelos entrevistados. Os dados obtidos foram tabulados em uma planilha eletrônica para uma melhor visualização dos resultados.

Ressalta-se que a presente pesquisa está em consonância com os preceitos éticos. O projeto foi submetido ao Comitê de Ética em Pesquisa da Universidade Federal do Rio Grande do Norte e aprovado por meio do parecer de no 2.825.025. Antes de cada entrevista lia-se o Termo de Consentimento Livre e Esclarecido (TCLE), onde eram explicados os objetivos do estudo e os benefícios que esses proporcionariam, e dessa forma estaria garantido a privacidade e o sigilo quanto aos seus nomes e as informações por eles prestadas. Em observância a isto, os entrevistados receberam códigos de identificação (Rio 01 a 14).

\section{RESULTADOS}

\section{Perfil dos participantes da pesquisa}

Do total de entrevistados, 71,4\% eram mulheres e 25,6\% homens. A idade média variou entre 21 e 57 anos, com uma maior participação na faixa etária entre 51 e 57 anos (50\% do total entrevistado). A maioria dos entrevistados $(85,7 \%)$ é natural do município de Rio do Fogo e reside na comunidade desde seu nascimento. Quanto aos aspectos habitacionais, $100 \%$ dos entrevistados possuem residência própria e apresentam condições básicas de moradia. Em relação à prestação de serviços públicos, foi observada carência no saneamento básico e coleta de lixo do munícipio.

Os dados sobre a formação escolar demonstraram $14,2 \%$ não possui instrução, $14,2 \%$ são alfabetizados, $43,0 \%$ possuem o ensino fundamental e $28,6 \%$ o ensino médio completo. Nenhum dos entrevistados possui nível técnico ou superior. No entanto, cerca de $54,1 \%$ expressam o desejo de dar continuidade aos estudos, seja para concluir o ensino médio ou iniciar um curso técnico ou superior. Quando questionados sobre a participação em algum curso relacionado às macroalgas marinhas e/ou ecologia de 
ambientes costeiros, $64,3 \%$ dos entrevistados afirmaram que já fizeram minicursos ou oficinas relacionadas a algum desses temas.

Quando indagados sobre a atividade produtiva relacionada às algas marinhas, 14,3\% exercem apenas a atividade de extrativismo nos bancos naturais, 7,1\% têm como atividade produtiva a extração das algas exclusivamente através do cultivo desses organismos e $78,6 \%$ realizam as duas atividades.

Atualmente todos os entrevistados fazem parte da associação cooperativista de beneficiamento de macroalgas marinhas (AMAR) a qual desenvolve a colheita de macroalgas nos bancos naturais, além de atividades de cultivo no mar. Os entrevistados afirmaram que os principais benefícios em participar desse grupo é a geração de renda, acesso à serviços, além do prazer/diversão durante as atividades produtivas.

\section{Conhecimentos tradicionais}

Na praia de Rio do Fogo, a mão de obra familiar é à base da atividade extrativista. Quando questionados, $69,2 \%$ dos entrevistados mencionaram que tiveram seu primeiro contato com a atividade de extração de macroalgas marinhas dos bancos naturais ainda na infância, entre 8 e 15 anos de idade, quando viam essa atividade sendo realizada por algum membro da família. Cerca de 15,4\% dos entrevistados iniciaram a atividade quando jovens, entre 16 e 29 anos, enquanto os demais participantes $(15,4 \%)$ aprenderam a atividade após a fase adulta, motivados pela necessidade, frente às dificuldades em encontrar emprego em outras áreas (Figura 2A).

Cerca de $84,6 \%$ dos entrevistados mencionaram ter aprendido a atividade extrativista de colheita das macroalgas marinhas nos bancos naturais, através da tradição familiar (Figura 2B). Os entrevistados citaram a figura da mãe e da avó como a principal transmissora desse conhecimento: "Aprendi com minha mãe, era uma tradição familiar (Rio 03, 47 anos). Aprendi com meus pais, que já realizavam a atividade (Rio 14, 50 anos)". Os outros $15,4 \%$, afirmaram ter aprendido a atividade através de um minicurso contemplado no projeto Desenvolvimento de Comunidades Costeiras (DCC), realizada pela Secretária de Aquicultura e Pesca do Governo Federal. O referido projeto foi desenvolvido na comunidade no ano de 2009 e tinha como objetivo consolidar e expandir o cultivo de algas de forma sustentável (BEZERRA, 2008).

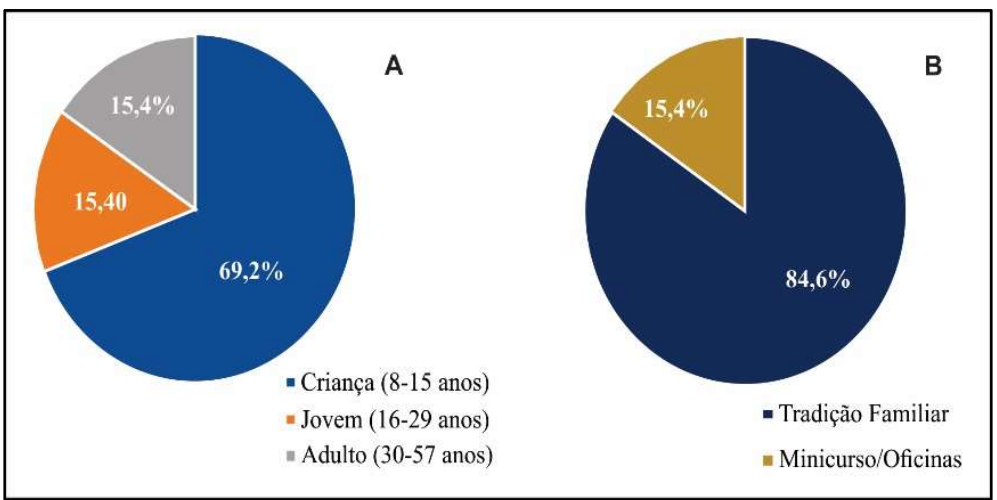

Figura 2: A. Primeiro contato com a atividade de colheita de alga dos bancos naturais; B. Forma de aprendizado da atividade extrativista em Rio do Fogo-RN/Brasil.

Quando indagados sobre o manejo e a ecologia da macroalga coletada (G. birdiae), cerca de 64,2\% 
dos entrevistados responderam que possuem conhecimentos acerca da biologia das espécies locais, nomeclatura, o processo de crescimento, habitat, formas de manejo e comportamentos de predadores. Quando questionados se algum fenômeno natural influenciava na atividade de colheita, $20,7 \%$ dos entrevistados desconhece essa informação, 36,4\% afirmaram que nenhum fenômeno natural influência na atividade e $42,9 \%$ argumentaram que a lua influencia o nível da maré e os períodos disponíveis de acesso aos bancos naturais. 'A lua influencia no nível da maré, seca o mar e facilita a extração de algas (Rio 07, 48 anos). A lua influencia no nível da maré (Rio 14, 50 anos)'. As fases da lua são sintetizadas pelos extrativistas a partir dos conhecimentos tradicionais adquiridos em suas vivências e interações com o ambiente natural.

Quando questionados sobre o motivo pelo qual iniciaram a extração de macroalgas dos bancos naturais, obtivemos como respostas mais comum: 'Curiosidade sobre o mar (Rio 04, 57 anos). Curiosidade sobre o mar, gerar renda. Além disso, essa atividade é uma terapia para mim (Rio 13, 52 anos)'. Os coletores também manifestaram o desejo em transmitir os seus conhecimentos para as futuras gerações. Cerca de $64,3 \%$ dos entrevistados ensinaram essa atividade para outras pessoas, principalmente para familiares, incluindo filhos e netos, garantindo assim a perpetuação desse conhecimento.

\section{Técnicas de colheita}

Para a colheita de algas dos bancos naturais os extrativistas utilizam apenas as mãos e/ou uma faca para coletar as algas, em uma profundidade de 30 a $60 \mathrm{~cm}$ (Figura 3A). 0 tempo médio utilizado na atividade pode variar entre 3 a 4 horas e cerca de 200 a $300 \mathrm{~kg}$ de macroalgas são extraídas dos bancos naturais em uma única colheita. Após a colheita as algas são transportadas em sacos de ráfia $(20 \mathrm{~kg})$ até a costa, espalhadas na areia e secas ao sol de forma uniforme, para posteriormente serem levadas para comercialização.

Em relação às dificuldades enfrentadas pelos coletores, cerca de $57,1 \%$ dos entrevistados afirmaram que a escassez e esgotamento dos bancos naturais na praia de Rio do Fogo e regiões vizinhas são os principais motivos que dificultam a continuidade dessa atividade. Os extrativistas expressam receio quanto à possibilidade do desaparecimento das macroalgas marinhas na região, pois as atividades estão enraizadas em suas rotinas.

\section{Técnicas aplicadas ao sistema de cultivo}

Os sistemas de cultivos desenvolvidos no local de estudo estão situados a 150 metros da praia e as estruturas utilizadas (balsas flutuantes) possuem um total de 50 metros, sendo subdivididas em 10 módulos de $5 \mathrm{~m} \times 5 \mathrm{~m}$ cada (Figura 3B). A balsa flutuante é confeccionada pelos próprios maricultores, geralmente homens, a partir de canos de PVC e cordas de polietileno de $6 \mathrm{~mm}$. Cada módulo é produzido utilizando 2 canos vedados nas extremidades e unidos por cordas de 5 metros nas laterais. Cerca de 8 a 10 redes tubulares de $5 \mathrm{~m}$ (semelhante às utilizadas no cultivo de mexilhões) são distribuídas na parte interna do módulo, presas aos canos com auxílio das cordas, com intervalos de $50 \mathrm{~cm}$ uma da outra. Para a fixação do sistema ao fundo são utilizadas duas âncoras (poitas) de aproximadamente $500 \mathrm{~kg}$, uma em cada extremidade da balsa. As 
poitas são confeccionadas com pneus e preenchida com uma massa de cimento e brita.

A metodologia adotada nesse cultivo utiliza a técnica de propagação vegetativa, onde são utilizados fragmentos de algas, coletadas diretamente dos bancos naturais, para produção de mudas. Para o processo de plantio, aproximadamente $2 \mathrm{Kg}$ de algas, recém coletadas dos bancos naturais, são inseridas no interior de cada rede tubular, com auxílio de um tubo PVC (Figura 3C).

No período de produção, que corresponde a cerca de 60 dias, ocorrem os procedimentos quinzenais (de acordo com o ciclo da maré) de manutenção e limpeza, tanto das estruturas de cultivo, como das macroalgas. Esse procedimento é necessário para a retirada das epífitas e de outros organismos incrustantes. Após o período de crescimento, as macroalgas são coletadas, colocadas em pequenas embarcações e levadas para a Associação de Maricultoras de algas de Rio do Fogo. Nesse local, a biomassa é espalhada em mesas de telas suspensas e expostas ao sol para secarem. A média do tempo de secagem é de até 2 dias. Durante este período, as algas são viradas pelo menos duas vezes ao dia para assegurar uma secagem uniforme. Após esse procedimento, elas são armazenadas em sacos de ráfia $(20 \mathrm{~kg})$ para posteriormente serem beneficiadas e/ou comercializadas.

\section{Comercialização}

Todos os extrativistas e cultivadores de macroalgas marinhas afirmaram exercer a atividade visando à geração de emprego e renda, o que contribui para o desenvolvimento social e econômico da comunidade. Nesse sentido, $61,9 \%$ dos extrativistas e $58,3 \%$ dos cultivadores afirmaram ser o principal responsável pelo sustento da família, evidenciando a importância econômica da atividade para a sua subsistência.

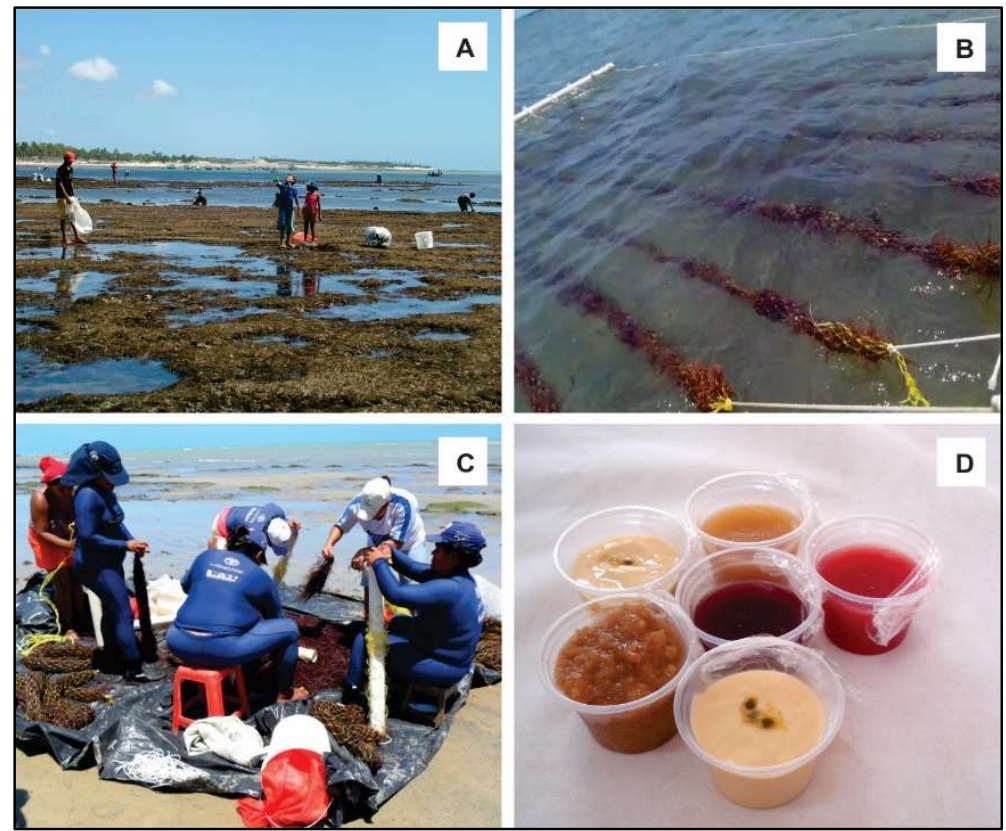

Figura 3: A. Colheita manual da macroalga G. birdiae realizada na zona intertidal; B. Estrutura de cultivo instalada no mar; C. Preparação do sistema de cultivo e preparação das mudas; D. Mousse, cocada e gelatina à base de algas produzidas pela associação AMAR, praia de Rio do Fogo, RN.

Geralmente a comercialização, tanto referente às macroalgas dos ambientes naturais (bancos algais), quanto dos sistemas de cultivo, é realizada pelos próprios coletores e produtores conforme o grau de 
beneficiamento. Os participantes afirmaram que a venda das macroalgas in natura não apresenta uma comercialização compensatória, uma vez que o valor gira em torno de $\mathrm{R} \$ 1,00$ por quilo da alga seca. Nessa negociação, geralmente a biomassa é vendida para atravessadores, que compram a produção por um valor muito abaixo do mercado e revendem com ganhos significativos. No entanto, quando há o processamento e beneficiamento da biomassa, há um retorno financeiro superior. Nesses casos são elaborados produtos com valor agregado mais elevado, tais como farinha de algas $(R \$ 25,00)$, biscoitos $(R \$ 10,00)$ e doces à base de algas (e.g. mousse, cocadas e gelatinas - R\$2,00) (Figura 3D).

\section{DISCUSSÃO}

O extrativismo dos bancos naturais e o cultivo de macroalgas marinhas são considerados tarefas domésticas, efetuada por vários membros de uma família (REBOURS et al., 2014; HART et al., 2014; SORIANO 2017). No entanto, o papel das mulheres tem sido fundamental nesse tipo de atividade, pois constituem cerca de $80 \%$ da mão de obra (SORIANO, 2017). Aliado a isso, sua imensa contribuição para a indústria tem sido amplamente demonstrada e avaliada em estudos de caso de sucesso (MSUYA et al., 2017). Em Rio do Fogo, grande parte dos extrativistas $(71,4 \%)$ são mulheres que desempenham essa atividade através de sua dedicação. Para elas, que em geral tem baixa escolaridade, a extração de algas é considerada como a principal ocupação e fonte de renda (REBOURS et al., 2014; SORIANO, 2017).

Geralmente a transmissão do conhecimento sobre as práticas tradicionais da colheita é sustentada na relação de afeto entre a mulher/mãe e seus filhos, na tentativa de passar seu saber para as gerações futuras. As mulheres geralmente executam a atividade com base no seu conhecimento tradicional sobre os recursos naturais locais (SORIANO, 2017). Esses "saberes" são desenvolvidos a partir das próprias experiências, observações das trocas de conhecimentos e da necessidade de se adaptarem ao ambiente onde vivem (FREITAS et al., 2012). Esse conhecimento é transmitido na maioria das vezes de forma oral, tornando possível o acesso às experiências vividas (BERKES et al., 2000; ARRUDA et al., 2001; DIEGUES, 2002; REYESGARCIA, 2009). Como visto anteriormente, em Rio do Fogo, a maioria dos extrativistas mencionou a figura materna como a principal fonte da transmissão desse conhecimento, evidenciando o papel importante das mulheres na transferência e construção desse saber. Essa transmissão de conhecimento garante que a tradição e a cultura dessa atividade produtiva, que está diretamente ligada ao trabalho, não desapareçam e sejam perpetuadas por gerações.

No que se refere ao manejo dos recursos naturais a maioria dos entrevistados $(64,2 \%)$, possui conhecimentos satisfatórios acerca do manejo e ecologia da macroalga coletada e cultivada (G. birdiae). As estratégias de manejo quando associada aos conhecimentos tradicionais, contribuem para a conservação da natureza in situ (DIEGUES, 2000; ARRUDA et al., 2001; DREW, 2005; PEREIRA et al., 2010). Dessa forma, as populações tradicionais desenvolvem seus próprios sistemas de conservação e manejo, existindo uma relação de harmonia, gratidão, respeito e cumplicidade com a natureza, sendo a causa direta da conservação ambiental (LÉVI-STRAUSS, 1989; MARQUES, 2001).

Diversos trabalhos já foram realizados com o intuito de identificar o conhecimento e o uso 
tradicional das macroalgas marinhas (REBOUS et al., 2014; O'CONNELL-MILNE et al., 2015; KITOLELEl et al., 2016; SORIANO, 2017; THURSTAN et al., 2018). Na Austrália foram avaliados o conhecimento tradicional e a importância das macroalgas, sendo identificados o uso em diversas atividades culturais, além da sua aplicação medicinal, na alimentação, ração, construção civil, entre outros (THURSTAN et al., 2018). Na Nova Zelândia, estudos foram realizados para avaliar o método tradicional de colheita do Karengo (Porphyra), sendo avaliados os métodos de colheita e como eles afetam a capacidade de regeneração da macroalga. Os autores identificaram que o método de colheita mais eficaz é o método tradicional (retirada manual), uma vez que resulta em uma rápida regeneração da macroalga (O'Connell-Milne \& Hepburn 2015). No arquipélago de Fiji, os conhecimentos tradicionais dos coletores de algas marinhas influenciaram na criação de técnicas eficientes de manejo e comercialização desses recursos naturais, resultando na implementação de um projeto visando o cultivo comercial (KITOLELEl et al., 2016). No Brasil, a colheita tradicional teve seu início na década de 60, principalmente para fins comerciais (REBOURS et al., 2014; SORIANO, 2017) e essa prática continua até os dias de hoje em algumas regiões do Nordeste (SORIANO, 2017).

A colheita de macroalgas é considerada uma das atividades extrativistas mais importantes em ambientes costeiros, sendo uma atividade rudimentar que não precisa de processos tecnológicos para sua execução (MONAGAIL et al., 2017; THURSTAN et al., 2018). Na praia de Rio do Fogo a principal espécie de macroalga explorada comercialmente é a G. birdiae (vulgarmente conhecida como cisco), sendo encontrada principalmente fixas à rochas, que ficam expostas durante a maré baixa. A sua colheita é realizada manualmente durante todo o ano, nas zonas do mesolitoral e infralitoral raso. Atualmente, é aplicado o método de colheita através do corte, que permite a regeneração mais rápida dos talos, garantindo que os bancos naturais sejam preservados e que os serviços ecossistêmicos fornecidos pelas macroalgas sejam garantidos para as gerações futuras.

Além disso, também foram desenvolvidas nessa região ações relacionadas ao cultivo de macroalgas marinhas com o intuito de conservar e preservar os bancos naturais. Cerca de 1 tonelada de macroalgas (1 balsa) é retirada dos sistemas de cultivo a cada ciclo (60 dias), e o valor obtido pela alga pode variar conforme o beneficiamento. Essa atividade tem a vantagem de ser relativamente simples e de fácil manejo, não requer grau de escolaridade por parte dos produtores e nem de grandes investimentos. O cultivo tem sido visto como uma alternativa viável para garantir a sustentabilidade da atividade e dos recursos algais, proporcionando para a região novos olhares e promovendo mudanças significativas nas formas de exploração desses recursos naturais (BEZERRA et al., 2010; REBOURS et al., 2014).

Quanto à comercialização, geralmente a estrutura utilizada pelas comunidades litorâneas apresentase com diferentes graus de hierarquia e formas de organização. A estratégia de comercialização é de pagar preços baixos aos extrativistas e produtores, e progressivamente, valores mais elevados a cada nível hierárquico da cadeia de comercialização (ALVES et al., 2003). Por esse motivo, muitos dos extrativistas e cultivadores de macroalgas preferem comercializar a biomassa algal processada e beneficiada, através da cooperativa, para obter ganhos mais significativos. Esse tipo de comercialização tem sido realizado ao longo dos últimos anos e tem contribuído como fonte de renda complementar para diversas famílias, gerando 
resultados econômicos satisfatórios e garantindo uma melhor qualidade de vida para os envolvidos.

\section{CONCLUSÕES}

A colheita de macroalgas dos bancos naturais e o cultivo de algas no mar desenvolvidos pela comunidade de Rio do Fogo apresentam características peculiares das populações tradicionais, sendo esta, de pequena escala e realizada de maneira artesanal. Os ambientes explorados diariamente pelos entrevistados mostram-se como um importante meio de subsistência para a comunidade, que atualmente enfrenta desafios no gerenciamento e manejo dos bancos naturais e nos sistemas de cultivos. Dessa forma, para alcançar a continuidade dessas atividades e gerar benefícios para a comunidade, com bases mais sustentáveis, é essencial levar em consideração os conhecimentos e práticas tradicionais da população local quanto ao uso e conservação desses recursos naturais.

AGRADECIMENTO: A todos da comunidade de Rio do Fogo, em especial os extrativistas e os cultivadores de algas marinhas da Associação de Maricultoras de algas de Rio do Fogo (AMAR) pela participação e apoio durante toda a pesquisa. Este estudo foi realizado com apoio da Coordenação de Aperfeiçoamento de Pessoal de Nível Superior - Brasil (CAPES). Código de financiamento 001.

\section{REFERÊNCIAS}

ALVES, R. R. N.; NISHIDA, A. K.. Aspectos socioeconômicos e percepção ambiental dos catadores de caranguejo-uçá Ucides cordatus (L., 1763) (Decapoda, Brachyura) do estuário de Rio Mamanguape, nordeste do Brasil. Interciência, v.28, n.1, p.36-43, 2003.

ARRUDA, R. S. V.; DIEGUES, A. C.. Saberes tradicionais e biodiversidade no Brasil. Brasília: Ministério do Meio Ambiente; São Paulo: Universidade de São Paulo, 2001.

BERKES, F.; COLDING, J.; FOLKE, C.. Rediscovery of traditional ecological knowledge as adaptive management. Ecological applications, v.10, n.5, p.1251-1262, 2000. DOI:

https://doi.org/10.1890/10510761(2000)010[1251:ROTEKA]2.0.CO;22

BEZERRA, A. D. F.. Cultivo de algas marinhas como desenvolvimento de comunidades. Dissertação (Mestrado em Desenvolvimento e Meio ambiente) - Universidade Federal do Rio Grande do Norte, 2008.

BEZERRA, A. D. F.; SORIANO, E.; M;. Cultivation of the red seaweed Gracilaria birdiae (Gracilariales, Rhodophyta) in tropical waters of northeast Brazil. Biomass and Bioenergy. v.34, n.12, p.1813-1817, 2010. DOI:

https://doi.org/10.1016/j.biombioe.2010.07.016

CALEGARE, M.; HIGUCHI, M.; BRUNO, A.. Traditional peoples and communities: from protected areas to the political visibility of social groups having ethnical and collective identity. Ambiente \& Sociedade. São Paulo, v.17, p.115-134, 2014. DOI: https://doi.org/10.1590/S1414753X2014000300008.
DIEGUES, A. C. O.. Mito Moderno da Natureza Intocada. 3. ed. São Paulo: USP, 2002.

DILLEHAY, T. D.; RAMÍREZ, C.; PINO, M.; COLLINS, M. B.; ROSSEN, J.; PINO-NAVARRO, J. D.. Monte Verde: seaweed, food, medicine, and the peopling of South América. Science, v.320, n.5877, p.784-786, 2008. DOI: https://doi.org/10.1126/science.1156533

DREW, J. A.. Use of traditional ecological knowledge in marine conservation. Conservation biology, v.19, n.4, p.1286-1293, 2005. DOI: https://doi.org/10.1111/j.15231739.2005.00158.x

FAO. Food and Agriculture Organization of the United Nations. The state of world fisheries and aquaculture. FAO, 2017.

FERNANDES, D.; FERNANDES, J. G.. A 'experiência próxima': saber e conhecimento em povos tradicionais. Espaço Ameríndio, v.9, n.1, p.127-150, 2015. DOI: https://doi.org/10.22456/1982-6524.53593

FORSTER, J.; RADULOVICH, R.. Seaweed and food security. In: TIWARI, B. K.; TROY, D. J.. Seaweed Sustainability: Food and Non-Food Applications. London: Elsevier, 2015. p.289313. DOI: https://doi.org/10.1080/09670262.2017.1365273

FREITAS, S. T.; PAMPLIN, P. A. Z.; LEGAT, J.; FOGAÇA, F. H. S.; BARROS, R. F. M.. Conhecimento tradicional das marisqueiras de Barra Grande, área de proteção ambiental do Delta do Rio Parnaiba, Piauí, Brasil. Ambiente \& Sociedade, São Paulo, v.15, n.2, p.91-112, 2012. DOI: http://dx.doi.org/10.1590/S1414-753X2012000200006 
GEERTZ, C.. O saber local: novos ensaios em antropologia interpretativa. Petrópolis: Vozes, 1997.

HART, G. M.; TICKTIN, T., KELMAN, D. WRIGH, T. A. D.; TABANDERA, N.. Contemporary gathering practice and antioxidant benefit of wild seaweeds in Hawai'i. Economic Botany, v.68, n.1, p.30-43, 2014. DOI: https://doi.org/10.1007/s12231-014-9258-7

HORA, N. N.; FERREIRA FILHO, H. R.; MARTINS, A. C. C. T.; FONCECA, M. J. C. F.. Traditional Knowledge and Biodiversity Conservation: Uses, Practices and Experience of Smallholders of a Community in Ananindeua/PA. Redes, v.20, n.2, p.308-335, 2015. DOI:

http://dx.doi.org/10.17058/redes.v20i2.4449

KITOLELEI, J. V.; SATO, T.. Analysis of perceptions and knowledge in managing coastal resources: A case study in Fiji. Frontiers in Marine Science, v.3, p.1-12, 2016. DOI: https://doi.org/10.3389/fmars.2016.00189

LÉVI-STRAUSS, C.. O Pensamento Selvagem. Campinas: Papirus, 1989.

MARQUES, J. G.. Pescando pescadores: ciência e etnociência em uma perspectiva ecológica. 2 ed. São Paulo: Núcleo de Apoio à Pesquisa sobre Populações Humanas e Áreas Úmidas Brasileiras, 2001.

MEKSENAS, P.. Pesquisa social e ação pedagógica: Conceitos, métodos e práticas. São Paulo: Layola, 2002.

MONAGAIL, M. M.; CORNISH, L.; MORRISON, L.; ARAÚJO, R.; CRITCHLEY, A. T.. Sustainable harvesting of wild seaweed resources. European Journal of Phycology, v.52, n.4, p.371390, 2017. DOI: https://doi.org/10.1080/09670262.2017.1365273

MOTA, D. M.; PEREIRA, E. O.. Extrativismo em Sergipe: a vulnerabilidade de um modo de vida. Campina Grande, Raízes, v.27, n.1, p.71-79, 2008.

MSUYA, F.; HURTADO, A.. The role of women in seaweed aquaculture in West Indian Ocean and Southeast Asia. European Journal of Phycology, v.52, n.4, p.482-494, 2017. DOI: https://doi.org/10.1080/09670262.2017.1357084

O'CONNELL-MILNE, S. A.; HEPBURN, C. D.. A harvest method informed by traditional knowledge maximises yield and regeneration post-harvest for karengo (Bangiaceae). Journal of applied phycology, v.27, n.1, p.447-454, 2015. DOI: https://doi.org/10.1007/s10811-014-0318-2

PEREIRA, B. E.; DIEGUES, A. C.. Conhecimento de populações tradicionais como possibilidade de conservação da natureza: uma reflexão sobre a perspectiva da etnoconservação. Desenvolvimento \& Meio ambiente, v.2, n.22, p.37-50, 2010. DOI: http://dx.doi.org/10.5380/dma.v22i0.16054

REBOURS, C.; SORIANO, E. M.; ZERTUCHE-GONZÁLES, J.A.; HAYASHI, L.; VÁSQUES, J. A.; KRADOLFER, P.; SORIANO, G.; UGARTE, R.; ABREL, M. H.; BAY-LARSEN, I.; HOVELSRUD, G.; RODVEN, G.; ROBLEDO, D.. Seaweeds: opportunity for wealth and sustainable livelihood for coastal communities. Journal of applied phycology, v.26, n.5, p.1939-1951, 2014. DOI: https://doi.org/10.1007/s10811-014-0304-8

REYES-GARCÍA, V.. Conocimiento ecológico tradicional para laconservación: dinámicas y conflictos. Papeles de relaciones ecosociales y cambio global, v.107, p.39-55, 2009.

SILVA, F. J. P.; FRAXE, T. J.. Saberes De Populações Tradicionais: Etnociência Em Processos De Bioconservação. Contribuciones a lãs Ciencias Sociales, n.8, p.14-14, 2013.

SORIANO, E. M.. Historical context of commercial exploitation of seaweeds in Brazil. Journal of Applied Phycology, v.29, n.2, p.665-671, 2017. DOI: https://doi.org/10.1007/s10811-016-0866-8

THURSTAN, R. H. BRITTAIN, Z.; JONES, D. S.; CAMERON, E.; DEARNALEY, J.; BELLGROVE, A.. Aboriginal uses of seaweeds in temperate Australia: an archival Assessment. Journal of Applied Phycology, v.30, n.3, p.1821-1832, 2018. DOI: https://doi.org/10.1007/s10811-017-1384-z

TORRES, P.; SANTOS, J. P.; CHOW, F.; SANTOS, D. Y.. A comprehensive review of traditional uses, bioactivity potential, and chemical diversity of the genus Gracilaria (Gracilariales, Rhodophyta). Algal research, v.37, p.288-306, 2019. DOI: https://doi.org/10.1016/j.algal.2018.12.009

VIERTLER, R. B.. Contribuições da antropologia para a pesquisa em etnobiologia. Atualidades em Etnobiologia e Etnoecologia. NUPEEA, SBEE, Recife, v.3, p.213-222, 2006.

A CBPC - Companhia Brasileira de Produção Científica (CNPJ: 11.221.422/0001-03) detém os direitos materiais desta publicação. Os direitos referem-se à publicação do trabalho em qualquer parte do mundo, incluindo os direitos às renovações, expansões e disseminacões da contribuiç̃o, bem como outros direitos subsidiários. Todos os trabalhos publicados eletronicamente poderão posteriormente ser publicados em coletâneas impressas sob coordenação da Sustenere Publishing, da Companhia Brasileira de Produção Científica e seus parceiros autorizados. Os (as) autores (as) preservam os direitos autorais, mas não têm permissão para a publicação da contribuição em outro meio, impresso ou digital, em português ou em tradução. 